\title{
Social Attitudes Toward Life Sentence in Relation to Minor and Juvenile Offenders - Replication of Edie Green's and Andrew Evelo's studies (2013)
}

\author{
Anetta Jaworska \\ Pomeranian University in Słupsk, 22 Arciszewskiego St., 76-200 Słupsk, Poland \\ E-mail address: jaworska.anetta@gmail.com
}

\begin{abstract}
The article points out some of the differences between Polish and American juvenile penal policy. It shows the differences between Polish and American society in terms of attitudes towards the use of life sentences without the possibility of parole (LWOP) for juvenile offenders. Studies also show that in both (Polish and American) societies, the tendency to impose the harshest sentences reflects the perceived purpose of the penalty.
\end{abstract}

Keywords: social attitudes; life sentence; juvenile offenders; minor; purpose of punishment

\section{INTRODUCTION}

The problem of social attitudes towards minor and juvenile delinquency has been thoroughly analyzed in the studies of Edie Green and Andrew Evelo [1]. They cover the attitudes of American society. In connection with a visible tendency of Polish society to adopt cultural influences coming from overseas [2] it seemed interesting to compare the American research with the opinions presented by Polish people. Although the principles of studies replication required measuring the same variables, we should note that the severity of the penalties applicable in the United States differs greatly from the severity of penalties applied (both in case of juvenile and adult offenders) in Poland.

Life sentence is currently the most severe punishment of all the possible imposition of penalties by the judiciary in Poland. On September 1, 1998 under the new Penal Code of 6 June 1997 (Journal of Laws of 1997, No 88 pos. 553), it replaced the death penalty applied earlier (on August 27, 2013, Poland ratified Protocol No 13 to the European Convention on Human Rights, completely abolishing the death penalty, also in times of war). In contrast to the American justice system, in Poland, life imprisonment cannot be applied to a person who was under 18 years of age at the time of committing the offense (art. $54 \S 2$ of the Penal Code). The Polish court also does not have the possibility to compel such restrictions that would deprive the convicted person of the opportunity to apply for early parole after 25 years of imprisonment (in exceptional cases -30 or 40 years). 


\section{PURPOSES OF PUNISHMENT AND ATTITIUDES TOWARDS ITS APPLICATION}

It has been previously demonstrated [1] that people are willing to opt for a more severe punishment for an offense if the dominant purpose of the penalty is to deter others from committing the crime or to isolate the criminal in order to prevent him/her from committing additional crimes. Much more liberal judgments about the severity of penalties are pronounced by those who would emphasize the correctional (rehabilitation) function of the imprisonment penalty. The perception the punitive or correctional character of punishment is therefore important in shaping public opinion concerning its severity.

Like in the studies of Edie Green and Andrew Evelo [1], the aim of my research was to determine what the social attitudes regarding the applicability of life sentence without the possibility of parole (LWOP, Polish KDPWBMWPZ) towards the juveniles are. The aim of the research replicated in Polish conditions, and the impulse to carry it out, is to demonstrate the need to open a scientific dialog on social attitudes regarding punishment of young offenders. The decisions in this regard will always rest with the government and it is difficult to expect that the results cited below will influence those decisions. However, they can provide information on social beliefs about these matters that are important for public security in the future.

In addition to examining attitudes towards LWOP, in our study we assess the opinions on the appropriateness of its application towards the juvenile and social attitudes associated with punishment. It was also examined how attitudes towards LWOP change depending on the age of the juvenile who has committed a crime.

\section{METHODS}

In the replication of the study by Green \& Evelo [1] I used a procedure identical with the studies of the American authors. My study assesses the social attitudes towards LWOP, made in relation to the age of the offenders and the nature of the offense, and depending on the purpose of punishment as perceived by the respondents.

\section{1. Research problems and hypotheses}

P.1. To what extent do people perceive life sentence without the possibility of parole as suitable for minors and juvenile offenders?

Attitude towards LWOP was measured by asking respondents to provide the minimum age at which LWOP should be used (if at all) as a punishment for eight different crimes.

Based on the results of previous studies showing that people understand the differences between developmental age and ability to incur criminal liability, the following hypotheses were posed:

H.1.a. Respondents generally will not support LWOP in relation to minors.

H.1.b. When respondents recognize the legitimacy of the use of LWOP towards juveniles, they admit that it should be reserved for juveniles who have committed serious crimes, especially murder.

P.2. What is the relationship between attitude towards LWOP and the perception of the purpose of the imprisonment sentence? 
Based on the previously cited studies showing that the perception of the purpose of punishment is associated with the attitude towards its severity, it was hypothesized that:

H.2. Those who perceive the purpose of punishment primarily as isolation and deterrent will support the possibility to adjudicate juvenile LWOP more often than those who see the correctional (rehabilitation) possibilities of a penalty.

\section{2. Subjects}

The study involved 696 people, 652 of whom were qualified for the final analysis of the results (the remaining results were rejected due to incompleteness, and other inconsistencies in the filling out of the questionnaires, that prevented interpretation of the data). Recruitment of respondents took place in two environments: university students in Poland $(\mathrm{N}=175)$ studying in full-time and part-time systems and the local community of Słupsk (medium-sized town) $(\mathrm{N}=151)$, where the research was carried out with the help of Pomeranian Academy students (other than the respondents) in a street survey. None of the study participants received remuneration.

The demographics are shown in Table 1.

Table 1. Demographic data of the analyzed population of students and local community.

\begin{tabular}{|c|c|c|c|c|}
\hline Demographic data & Students & $\begin{array}{c}\text { Local } \\
\text { community }\end{array}$ & Total & Census 2011 \\
\hline $\mathbf{n}$ & 175 & 151 & 326 & 38511.8 \\
\hline Age (in years) & & & & \\
\hline The median & 22 & 38 & & 38.1 \\
\hline Minimum & 20 & 18 & & - \\
\hline Maximum & 47 & 78 & & - \\
\hline Gender & & & $62.0 \%$ & $51.6 \%$ \\
\hline Women & $66.9 \%$ & $56.3 \%$ & $38.0 \%$ & $48.4 \%$ \\
\hline Men & $33.1 \%$ & $43.7 \%$ & & \\
\hline Ethnic-national & & & $99.1 \%$ & $99.3 \%$ \\
\hline identity & $98.9 \%$ & $99.3 \%$ & $0.9 \%$ & $0.7 \%$ \\
\hline Poland & $1.1 \%$ & $0.7 \%$ & & \\
\hline Other & & & $5.8 \%$ & NDA \\
\hline Political views & $5.1 \%$ & $6.6 \%$ & & NDA \\
\hline Very conservative & & $20.5 \%$ & & \\
\hline Conservative & & & & \\
\hline
\end{tabular}

\footnotetext{
${ }^{1}$ Narodowy Spis Powszechny Ludności i Mieszkań 2011. (2013). Ludność. Stan i struktura demograficznospołeczna. GUS: Warszawa. http://www.stat.gov.pl/cps/rde/xbcr/gus/LUD_ludnosc_stan_str_dem_spo_NSP2011.pdf downloaded on 18.12.2013
} 


\begin{tabular}{|c|c|c|c|c|}
\hline Moderate & $36.0 \%$ & $42.4 \%$ & $39.0 \%$ & NDA \\
\hline Liberal & $29.7 \%$ & $25.2 \%$ & $27.6 \%$ & NDA \\
\hline Very liberal & $6.9 \%$ & $5.3 \%$ & $6.1 \%$ & NDA \\
\hline
\end{tabular}

NDA $=$ no data available

The results in Table 1 show the percentage distribution of respondents in terms of gender, national-ethnic identification (Polish, Kashubian, Belarussian), and the expressed political beliefs. Demographic data are shown against the background of Polish population, analyzed by the most recent Census of Population 2011 [3]. The data allow concluding that the respondents were generally similar to the Polish community at large in terms of median age and national-ethnic identification. Three of the surveyed participants had other than Polish ethnic nationality.

In further analysis, as in the original study, students' and local community representatives' results have been combined.

\section{3. The research procedure}

The studies were carried out on 3-21 November 2013. All the data were collected in writing, using a questionnaire containing questions about demographics, attitudes towards severity of punishment regarding juveniles and the purpose of imprisonment sentencing.

The questionnaire of attitudes towards punishment towards minors and juveniles was built on the basis of the data contained in the original studies of Greene \& Evelo [1] adapting the definitions of the offenses to those of the Polish Penal Code (Act of 6 June 1997.The Penal Code, Art. 1 Journal of Laws of 1997 No 88 pos. 553). The questionnaire contains eight offenses for which an acceptable, according to the respondents, penalty was determined: murder of a stranger, murder of an aggressive parent, car theft, burglary, grievous bodily harm, sexual assaults, robbery with a deadly weapon, drug trafficking.

Next to each crime a list of all age groups from 10 to 21 years was presented with the possibility of selecting from what age it should be possible to impose LWOP with the option to answer "should never be sentenced to life imprisonment without the possibility of parole" ("never") and "punishment should be applied only to adults" ("OTA").

The demographic part of the questionnaire (in accordance with the original study) asked the respondents to indicate their age, gender, ethnicity and political views.

Finally, in order to determine the purpose of imprisonment perceived by the respondents, the Sentencing Goals Scale was applied [1]. Just as in the original studies, the 20 -item scale consisted of four subscales, each designed to assess attitudes toward a particular sentencing goal (Incapacitation, Rehabilitation, Retribution, and Deterrence), with 5 items per subscale. Each item was a statement. Respondents indicated their agreement with these statements on a 1 (strongly disagree) to 7 (strongly agree) Likert-type scale. Each subscale could therefore be rated with 5 to 35 points. The lower the score, the lower the value attributed to the given goal of punishment.

\section{RESULTS}

Given the nature of the analyzed data, the attitudes of the participants were divided into two dichotomous groups, depending on the age of the offender, at which the respondents were 
willing to support the legitimacy of the use of LWOP for a given offense. In each group the percentages were compared using confidence intervals (CI).

Comparative analysis applied to the two different age groups towards which the respondents were willing to declare the legitimacy of using LWOP: minors (10-17 years) and juveniles (18-21), and the respondents who marked that for the given offense the LWOP "should never be applied" ("never'), and that "should be applied only to adults" ("OTA").

This division of groups allowed assessing social attitudes towards LWOP with regard to minors (10-17 years).

The next step was to refer the results to the goals of imprisonment sentence indicated by the respondents. The relationship between the perceived goal of punishment and supporting LWOP towards minors and juveniles was determined using regression analysis.

\section{1. Support to the use of LWOP}

The results of Attitudes towards Punishment Questionnaire are presented in Table 2. The results were divided into categories, depending on the age of the offender, in which the respondents could recognize the legitimacy of the use of LWOP. The first group consisted of the people who accepted the possibility to sentence LWOP to minors (10-17 years), while the second group accepted that the penalty could be applied to juvenile offenders (18-21), adults or that it should never be used in response to committing the offense.

Table 2. The percentage of respondents accepting the legitimacy of sentencing LWOP for committing the given offense to the accused of a specific age.

\begin{tabular}{|c|c|c|c|c|c|}
\hline & & Minors & & Non-minors & \\
\hline Offense & $n$ & $\%$ & $90 \%$ CI & $\%$ & $90 \%$ CI \\
\hline Murder of a stranger * & 326 & 40 & {$[36-44]$} & 60 & {$[56-64]$} \\
\hline Sexual assault * & 325 & 36 & {$[32-40]$} & 64 & {$[60-68]$} \\
\hline Murder of aggressive parent * $^{*} 326$ & 30 & {$[26-34]$} & 70 & {$[66-74]$} \\
\hline Robbery with a deadly weapon* & 324 & 27 & {$[23-31]$} & 73 & {$[69-77]$} \\
\hline Grievous bodily harm * & 326 & 23 & {$[19-27]$} & 77 & {$[73-80]$} \\
\hline Drug trafficking * & 324 & 17 & {$[14-20]$} & 83 & {$[80-86]$} \\
\hline Burglary * & 323 & 12 & {$[09-15]$} & 88 & {$[85-91]$} \\
\hline Car theft * & 326 & 10 & {$[07-13]$} & 90 & {$[87-93]$} \\
\hline
\end{tabular}

Notes: Category "minor" includes respondents who felt that for the offense LWOP should be currently applied to people who are at the age of 10-17 years; category of "non-minor" includes respondents who felt that for the given offense LWOP should be applied at the earliest to minors and juveniles (10-21 years), only to adults, or in general should not be used. $\mathrm{CI}=$ confidence interval; $\mathrm{H} .0=.50$.H.1 a P minors $<\mathrm{P}$ non-minors; $\mathrm{LWOP}=$ penalty of life imprisonment without the possibility of parole.

$* \mathrm{p}<.05$

For any of these crimes the proportion of respondents allowing the use of LWOP towards juvenile offenders, including the CI, was not higher than $50 \%$. For all eight crimes, there were many fewer respondents who felt that this punishment could be applied to minors 
than those who felt it could be applied to juveniles, adults, or that in general should not be used.

According to hypothesis H.1a, it was expected that respondents would not be willing to grant the possibility of sentencing LWOP to minors, and according to hypothesis H.1.b, that people would approve such a legal possibility, but only for offenses concerning human life, not for crimes not related to murder. According to the procedure of calculation used by Greene and Evelo [1], to verify this hypothesis, we calculated that for each offense, the percentage of people willing to allow this type of sentencing for juveniles was significantly different than the percentage of respondents not supporting that option. 90\% CI was calculated for the percentage of respondents who supported sentencing LWOP to minors and for the percentage of respondents who considered the minimum age at which a person can be punished with LWOP to be 18 years or who did not admit such a possibility to punish people for the given offense. The significance level was set at $p<0.05$. In cases where the CI does not exceed $50 \%$, it was considered as evidence of significant differences in attitudes between the respondents [1].

It turned out, that in the case of all crimes - both related and unrelated to murder, the percentage of respondents who would support the application of LWOP towards minors (Table 2, column 2), was significantly lower than the percentage of those who do not favor the possibility of applying the penalty towards minors (column 4). These differences were statistically significant. This result indicates that the respondents are not willing to support sentencing LWOP to minors, even in the case of crimes such as murder. Even in the case of murder by a minor of an unknown person or a parent, being abusive and aggressive towards the minor, a substantial majority of respondents do not consider the possibility of imprisoning the offender without the possibility of leaving the prison at any time in the future. This result confirms hypothesis H.1.b and is different from the results obtained by Greene and Evelo [1] in the United States.

A slightly different picture appeared upon the analysis which took into account only those respondents who allowed the possibility of sentencing LWOP, for at least some age groups of offenders committing these acts (see. Tab.3). In this analysis, the respondents who stated that for the given offense LWOP should never be used, regardless of the age of the offender, were not taken into account (the number of respondents declaring that LWOP should never be used varies considerably, depending on the type of crime and fluctuates within $n$ : 174-286).

Table 3. The percentage of respondents admitting the legitimacy of sentencing LWOP for committing the given offense excluding the respondents who chose the option "LWOP should never be used".

\begin{tabular}{|c|c|c|c|c|c|}
\hline & & Minors & & Adults & \\
\hline Offense & $n$ & $\%$ & $90 \%$ CI & $\%$ & $90 \%$ CI \\
\hline Murder of a stranger * & 286 & 45 & {$[40-50]$} & 55 & {$[50-60]$} \\
\hline Sexual assault * & 278 & 42 & {$[37-47]$} & 58 & {$[53-63]$} \\
\hline Murder of aggressive parent * & 260 & 37 & {$[32-42]$} & 63 & {$[58-68]$} \\
\hline $\begin{array}{c}\text { Robbery with a deadly weapon } \\
*\end{array}$ & 246 & 35 & {$[30-40]$} & 65 & {$[60-70]$} \\
\hline \begin{tabular}{c} 
Grievous bodily harm * \\
\hline
\end{tabular} & 230 & 33 & {$[28-38]$} & 77 & {$[72-82]$} \\
\hline
\end{tabular}




\begin{tabular}{|c|c|c|c|c|c|}
\hline Drug trafficking * & 202 & 28 & {$[23-33]$} & 72 & {$[67-77]$} \\
\hline Burglary * & 178 & 21 & {$[16-26]$} & 79 & {$[74-84]$} \\
\hline Car theft * & 174 & 17 & {$[12-22]$} & 83 & {$[78-88]$} \\
\hline
\end{tabular}

Notes: Category "minor" includes respondents who felt that for the offense LWOP should be currently applied to people who are in the age of 10-17 years; category of "adults" includes respondents who felt that for the given offense LWOP could be applied to minors and juveniles (10-21 years) as well as respondents who felt that for the given offense LWOP should be applied only to adults. Respondents who felt that in general LWOP should not be used were excluded from the analysis. $\mathrm{CI}=$ confidence interval; H.0 = .50. H.1.a P minors $<\mathrm{P}$ adults; LWOP = penalty of life imprisonment without the possibility of parole. $* \mathrm{p}<.05$

Most people declared that car theft should not be punished with LWOP, while the offense for which the respondents most frequently were willing to support such a penalty was murder of a stranger. These results are consistent with the results of Greene and Evelo [1], although it should be noted that in this respect Polish respondents in a slightly smaller proportion were willing to sentence LWOP for a murder of a stranger, and a considerably higher number for car theft.

The results presented in Table 3 indicate that among the respondents stating the possibility of sentencing LWOP in relation to different types of crime, there are significant differences of opinion in allowing the applicability of the penalty, depending on the age of the offenders. American research [1] revealed that over $50 \%$ of the respondents supporting the use of LWOP indicated that it could be imposed at the minimum age range of 10-17 years. These studies showed that the age of the offender does not have a significant impact on public opinion, in terms of allowing the use of LWOP. The results presented in Table 3 show a different picture of the attitudes of Polish respondents. Among the respondents allowing the use of LWOP, a significantly higher percent would allow this penalty only for persons over 18 years of age. For most offenses, except for murder of a stranger (CI level analysis), the respondents found that sentencing LWOP was appropriate only for adults. Only in the case of a murder of a stranger, did this group of respondents consider that the severity of the penalty should be the same for minors, juveniles and adults. It therefore appears that the respondents perceive differently the responsibility of an adult and of a minor, noting that the latter is not fully able to bear such severe criminal liability without the chance to change his/her life.

In order to definitely and accurately assess what the attitude of the respondents was, towards the possibility of applying LWOP towards minors is, we excluded the respondents who felt that for the given offense LWOP should be applicable only to adults or should not be applied at all (the number of excluded respondents oscillated within n: 31-129, depending on the type of crime).

It was then analyzed whether the respondents were more likely to choose a minimum age of sentencing LWOP for younger minors (10-15 years old), or only older minors (16-17 years) (see. Tab.: 4). These age categories were chosen because of the need to reproduce most accurately the American studies [1]; although in contrast to the United States, in Poland a minor is understood only as a person who has reached 13 years of age (until this time the guardians take the responsibility for his/her actions). As shown in Table 4, in contrast to American studies, a smaller proportion of the respondents allowing sentencing LWOP for minors felt that such a penalty should also be currently applied to younger minors, for all categories of offenses (Table 4, column 2). The percentage of the respondents supporting sentencing LWOP for minors, who chose the age between 10-15 years as the minimum age 
for this penalty, was generally lower than the percentage of the respondents who allowed the possibility of applying this penalty to minor offenders at the age of 16 . Such a pattern appeared for most of the abovementioned categories of offenses.

Significant differences in this field appeared only for a murder of a stranger. This result suggests that in the case of an offense involving a murder of a person who did not cause harm to the offender (as opposed to violent parents), among people supporting the use of LWOP of minors, the majority approves of such a penalty for early age offenders.

Table 4. Percentage of respondents recognizing the legitimacy of sentencing LWOP for committing the offense, excluding the respondents who chose the option "LWOP should never be used" and "LWOP should be used only for adults".

\begin{tabular}{|c|c|c|c|c|c|}
\hline & & $\begin{array}{c}\text { Younger } \\
\text { minors }\end{array}$ & & Older minors & \\
\hline Offense & $n$ & $\%$ & $90 \%$ CI & $\%$ & $90 \%$ CI \\
\hline Murder of a stranger * & 129 & 51 & {$[44-58]$} & 49 & {$[42-56]$} \\
\hline Sexual assault * & 117 & 28 & {$[21-35]$} & 72 & {$[65-79]$} \\
\hline Murder of aggressive parent * & 97 & 27 & {$[20-34]$} & 73 & {$[66-80]$} \\
\hline $\begin{array}{c}\text { Robbery with a deadly weapon } \\
*\end{array}$ & 87 & 24 & {$[16-32]$} & 76 & {$[68-84]$} \\
\hline Grievous bodily harm * & 76 & 26 & {$[18-34]$} & 74 & {$[66-82]$} \\
\hline Drug trafficking * & 56 & 27 & {$[17-37]$} & 73 & {$[63-83]$} \\
\hline Burglary * & 38 & 29 & {$[17-41]$} & 71 & {$[59-83]$} \\
\hline Car theft * & 31 & 16 & {$[05-27]$} & 84 & {$[73-95]$} \\
\hline
\end{tabular}

Notes: Category "younger minors" includes respondents who felt that for the given offense LWOP should be currently applied to people who are in the age of 10-15 years; category of "older minors" includes respondents who felt that for the given offense LWOP should be applied at the earliest to older minors at the age of 16-17 years. Respondents who felt that in general LWOP should not be used or that it should be applied only to adults were excluded from the analysis. $\mathrm{CI}=$ confidence interval; H. $0=.50$. H.1. a P younger minors $<\mathrm{P}$ older juveniles; LWOP $=$ penalty of life imprisonment without the possibility of parole.

$* \mathrm{p}<.05$

\section{2. The influence of the goal of penalty}

It was assumed that ideologies related to the carrying out of a prison sentence, as declared by the respondents, would be associated with the acceptance of LWOP sentencing. In the studies we applied the original Sentencing Goals Scale used by Greene and Evelo [1] and translated into Polish (Skala Celów Kary, transl: Anetta Jaworska). Due to the fact that the psychometric characteristics of the questionnaire have not yet been thoroughly tested (as in the original, American version), in the following analysis (like in the studies of Greene \& Evelo), we did not outline the four separate dimensions on the scale, but a factor analysis based on the principal Varimax components was made. The results of the analysis showed that the best solution would be to operate only on two factors: the penal factor - associated with deterrence, isolation and revenge and the correctional factor - associated with social rehabilitation. In the Polish version of the scale, the first of these factors explains up to 64.7 of the ratings variance, while the second factor $-24.4 \%$ of the total variance. Cronbach's alpha 
reliability coefficient for the first factor (utilitarian goals) is 0.96 and for the second factor (rehabilitation) Cronbach's alpha $=0.82$.

It was expected that the ideology (perceived goal) associated with the utilitarian nature of the penalty (deterrence, revenge and isolation) would be to a greater extent related to supporting LWOP. Operationalization of the support to LWOP was made by determining the attitude towards the possibility of delivering the penalty to different age groups, or that for a given offense the penalty should not be used at all. Like in the research of Greene and Evelo [1], it was found that people who believe that the use of LWOP penalty is never appropriate or are willing to support sentencing LWOP only to adults, are to a lesser extent in favor of its use than those who are willing to support sentencing LWOP even for people starting at 10 years of age. Recoded statistical data thus contain four groups of responses: 0-1: "penalty appropriate for minors", 2 "penalty appropriate for juveniles", 3 - "penalty appropriate only for adults", 4 - "penalty should never be used."

To check the relationship between the perceived goal of the penalty of imprisonment: utilitarian or correctional and the support for LWOP, we have carried out a regression analysis in which the predictors were the perceived goals of penalty, and the outcome variable - the attitude towards LWOP. A statistically significant result was obtained $F(2,323)=230.43$, p $<0.001, \mathrm{R} 2=0.59,95 \%$ CI $[0,52-0,65]$. As expected, the perception of the goal of the penalty primarily as utilitarian (deterrence, revenge and isolation) correlated positively and significantly with supporting LWOP $\beta=0.52$, t $(325)=13.64, \mathrm{p}<0.001$, SR $2=0.59$, while the perception of the penalty as correctional (resocialization), significantly and negatively correlated with supporting LWOP $\beta=-0.42, \mathrm{t}(325)=-11.05, \mathrm{p}<0.001$, SR $2=0.38$.

\section{CONCLUSIONS}

The presented results demonstrate significant public support for the policy of dealing with juvenile offenders based more on the idea of education and social rehabilitation than retribution. All the obtained results allow concluding that the respondents generally do not support the possibility of sentencing LWOP for minors. In terms of the applicability of the penalty to minors, punishing any of the listed offenses was supported by more than $50 \%$ of respondents. A significantly smaller proportion of respondents felt that this penalty should be applied to minors relative to proportion of those who expressed the opinion that it should be reserved for juveniles and adults, or that in general it should not be used. This result indicates that these respondents are not willing to support sentencing LWOP to minors, even in case of crimes such as murder. This result is consistent with the results of the American study, although in the case of American society, the respondents were much less restrictive about the possibility of using LWOP penalty for the murder of a stranger (for this act the respondents were willing to sentence LWOP from an early age).

A slightly different picture appeared from the analysis that took into account only those respondents who supported the possibility of sentencing LWOP, within certain age groups of offenders committing the abovementioned acts (excluding the respondents that do not support the use of LWOP). In this case, the crime for which respondents most frequently were willing to support such a penalty was, as in the USA, murder of a stranger, while the offense for which the fewest people would impose such a sentence was a car theft. These results are consistent with the results of the American study, although it should be noted that in this respect Polish respondents in a slightly smaller proportion than the Americans were willing to sentence LWOP for a murder of a stranger, and in a considerably higher proportion for a car 
theft. The lower percentage of the people supporting the most severe punishment for specific offenses is therefore convergent with the American study, but the severity of the Polish respondents in terms of the willingness to sentence LWOP for car theft, burglary is much more considerable. It seems that a possible cause of these differences is a higher insecurity attached to common crimes in Poland than in the United States, given the standard of living and economic status - a higher value is attributed to material assets (cars, houses, equipment).

The presented analysis of the study also indicated that among the respondents allowing the use of LWOP, a significantly higher proportion of people admitted the possibility of applying the penalty only to people over the age of 18 for most offenses. Only in the case of murder of a stranger did this group of respondents consider that the severity of the penalty should be the same for minors, juveniles and adults. For all categories of offenses, a smaller proportion of people allowing the use of LWOP towards juveniles were also willing to agree with such a possibility in the case of the youngest (10-15 years) offenders. Such a pattern was visible in case of most of the described categories of offenses, except for murder a stranger.

Polish respondents perceive therefore that a minor offender is not adult enough and able to bear the extreme criminal liability of never receiving the chance to change his/her life. The reason for the differences in Polish and American studies is the fact that the situation of Polish children living in pathological families has recently been strongly publicized and discussed. Strongly publicized media campaigns against violence towards children, including murders of children by the parents, are likely to increase social empathy and compassion for the youngest ones, and thus illuminate that the potential cause of behavioral disorder and juvenile delinquency lie in the inappropriate, and sometimes extremely negative parenting attitudes and the lack of proper, prompt and effective intervention of the institutions responsible for the care of the family. Understanding the reasons for the development of behavioral disorder among minors could lead to treating them as less criminally responsible than adults.

The studies have also shown a relationship between the perceived ideology of punishing criminals and willingness to impose extreme forms of imprisonment. As expected, the perception of penalty in terms of utilitarian goals proved to be associated with a more severe approach to punishing juveniles, including the possibility of LWOP, while the perception of penalty as a means of recovery for criminals turned out to be related to the opinions supporting the lack of need for LWOP at all or only for persons who have reached the age of 18 .

The presented study showed that despite the views propagated by the media and, one must note, existent dangers associated with the most violent offenders leaving prisons, Polish society, to a lesser extent than the American, is convinced of the merits of the application of lifetime imprisonment without the possibility of early parole. In contrast to the American society, Polish respondents to a lesser extent are also willing to punish minors with this penalty.

Severe condemnation and a willingness to impose the most severe prison sentence, both in Poland and in the United States were associated with crimes against life. Respondents in both countries, however, were inclined to see extenuating circumstances, recognizing that killing a person who was using physical abuse (abusive parent of a child) deserves a lesser sentence. Even for the most serious crimes, the respondents stated that most severe imprisonment penalty, without providing any possibility of a second chance in life, to a greater extent should be used with respect adults than towards minors. Even fewer people were willing to believe that the penalty should be applied to the offenders aged between 10-15 years. The study also showed that the ideology of punishment in its broad understanding could influence the decisions about the severity of penalties, including minors (and even 
children). It seems therefore, that statutory criminal law has strong ideological basis, and the severity of the punishment of offenders, to a greater extent, depends on the perceived goal of penalty than on the real effects of crime prevention.

\section{References}

[1] Greene, E., Evelo A.J., Law and Human Behavior 37(4) (2013) 276-289

[2] Maliszewski, T., Education at the Junction of Cultures (2008) 212-264

[3] Narodowy Spis Powszechny Ludności i Mieszkań 2011. (2013). Ludność. Stan i struktura demograficzno-społeczna. GUS: Warszawa.

http://www.stat.gov.pl/cps/rde/xbcr/gus/LUD_ludnosc_stan_str_dem_spo_NSP2011.pdf 